Type 2.-The patient with freguent micturition, diffi. culty, and a vell-marked enlargement of the prostate, and about 6 oz. or $S 0 \%$ of residual urine.

It is obvious that an operation will have to be done or catheter life commenced. In such a case the decision should not be left until an attack of retention has occurred. The danger of the catheter, whether it is passed as an emergency for the relief of an attack of retention or whether it is used regularly to remove residual urine, is that sepsis is inevitable. The result of introduction of bacteria is cystitis, and this is immediately followed by ascending pyelonephritis or surgical kidney.

After ten or fourteen days the attack usually subsides, but the urine remains cloudy. Recurrent attacks occur after fatigne, constipation, exposure to cold, dietetic in. discretion, and such causes, and it becomes apparent that the patient is gradually going downhill. The condition that we know as urinary septicaenia is developing.

In the great majority of patients on catheter life, whether they suffer from uxinary septicaemia or not, there comes a time when, from increasing difficulty in passing the catheter or from haemorrhage or pain in passing it, catheterization is no longer possible and an operation must be done.

I have already stated my view that patients should never be allowed to get into this condition, and that early operation should be performed in order to avoid it. If infection has already occurred and urinary septicaemia has developed, the first aim of treatment should be to get rid of the combined back pressure and sepsis. This is done by draining the bladder.

A suprapubic cystotomy is performed under local anaesthesia or under gas and oxygen, and the patient is given large quantities of fluids and hexamine or salol. Rectal administration of saline may be necessary, for the patient may be unable to take sufficient fluid by the month. At the same time the bladder is flushed by constant irrigation through a catheter tied in the urethra and a Hamilton Irving suprapubic box.

Removal of the prostate is deferred until the urine is sufficiently clear and the tests of the renal function are satisfactory and the symptoms of uraemia and sepsis have disappeared.

Type 3.-The patient complains of a little difficulty in starting micturition, and may get up several times at night. The prostate is found to be very large and elastic. There may be little residual urine.

In this class of case the patient has difficulty in realizing that an operation is necessary. He objects, as he puts it, to having an operation done when he is quite well. He is, however, in a dangerous position. At any time, from slight causes, such as fatigue, chill, etc., he may have an attack of retention, necessitating the passage of a catheter under difficult conditions, with the possibility of septic infection, or lie may gradually develop the condition of chronic retention of urine, with back pressure effects in the kidneys, that I have described. These issues should be clearly placed before him and an operation recommended to prevent them.

There is another outcome which you do not hear very much about. An adenomatous prostate occasionally becomes malignant. There are, I find, two types of malig. nant prostate with which we have to deal. In the one the prostate is hard, nodular, and fixed, and tie change has evidently been malignant from the commencement; in the other there is an elastic adenomatous prostate, which at one part is hard and leathery and becoming fixed. Further, there are some cases in which an enlarged prostate, adenomatous on rectal palpation, shells out easily and completely, but the pathologist reports that at one part in the gland the appearances are those of a malignant growth.

This malignant development does not take place in a large percentage of cases, but it is met with sufficiently often to make it necessary to consider it in estimating the prognosis of a case of enlarged prostate treated without operation.

\section{INDICATIONS FOR OPERATION.}

In discussing the question of operation as opposed to catheter life with your patients, I would like you to consider the following points:
1. Enlargement of the prostate is a progressive disease, the rate of increase of which we cannot foretell.

2. As the prostate enlarges, the patient grows older, and is less able to withstand the effect of uraemia or sepsis or the effects of a severe operation.

3. When the symptoms become acute, much damáge has already been done to the kidneys; and although improvement may follow operation, much of the damage is permanent.

4. Some adenomatous prostates become malignant.

5. The mortality of catheter life is higher than that of prostatectomy.

6. A very large proportion of the cases of enlarged prostate treated by catheter are forced eventually to undergo operation.

7. The prognosis in such cases is much graver than if the operation had been performed without a period of catheter life.

8. A large proportion of the deaths after prostatectomy. are due to the sepsis caused by pre-operative catheterization or the back pressure and renal inefficiency due to delay in submitting to operation.

\section{THE TEACHING AND STUDY OF HUMAN ANATOMY. \\ BY \\ RICHARD J. A. BERRY, M.D., F.R.C.S., F.R.S.EDIN., PROFESSOR OF ANATOMY, INCLUDING HISTOLOGT, IN THE
CNIVERSITY OF MELBOURNE.}

Contrary to currently accepted opinion, human anatomy is not a study of the dead, but of the living. It merely utilises the dead as a partial and imperfect means to an end. That end seeks to establish the essential foundations upon which the practice of medicine is based, and hence the place of anatomy in the medical curriculum. It is not a thing apart from the curriculum, but belongs to every part of it. Anatomy also endeavours to promulgate the welfares of peoples by the study and interpretation of the biological laws of life. The former is the particular province of the student of medicine and the surgeon, whilst the latter belongs more exclusively to the professional anatomist. It should, however, be the aim of both to correlate the study of life with that of disease, and hence anatomy, as a part of the medical curriculum, should lead up to the study of medicine and surgery. If anatomy fails in either or both of these objects it can hardly expect either the recognition or the prominence in our curricula to which it is really entitied.

That anatomy has too long been regarded and treated as a study of the dead is only too probable. Its textbooks and teachings still reflect the multiplicity of detail of the mid-Victorian period, but do so in an even more aggravated form, whilst the diporce from the clinician is more com: plete to day than at any other period in the history of medicine. If anatomy is to be taught to medical students on purely academic lines apart from hospitals and the study of disease, in water-tight compartments of medical curricula, and with examinations which are mere feats of memory, so long is it certain that as thus taught, crammed, and forgotten, it subserves no useful purpose in the study of disease.

This conception of anatomy as an academic study of the dead has resulted in an orer-accumulation of largely un. important detail. The unfortunate student of medicine is unable to differentiate between the vital and the useless. To him articulations of carpal bones are of equal import with: lymph glands, probably more, because he can see the former and very seldom sees the latter. Relations of trivial arteries-which the surgeon seizes and ties-are matters to be learnt by rote, and bulk, in the student's eyes, as largely as great veins, epiphyses, and lymphatics. Muscles are studied with a meticulous attention to trivial details of osseous attaclıment, but with no conception of their collective functions in the living subject. Swamped in morass of detail the student can no longer see the distant tree of knowledge for the mud.

Man is an animal-a highly specialized one in some directions, much less so in otliers. In his bodily structure and functicns he conforms in every detail to the great and 
universal laws of nature, and hence the student of anatcmy must understand these laws and realize that they are the laws of the living and not of the dead. Anatomy is not, therefore, merely a study of structure. It is rather a study of the modification of structure to function, of impairment of function, and of the different vital conditions under which these functions are carried out. Properly interpreted, stuch a study leads logically and inevitably to an understanding of the phenomena of life as well as to those of disease. Its teaching necessarily implies a wider vision than is to be obtained from the dissecting-room cadaver, and compels from the expert some general acquaintance with embryology, histology, biology, and anthropology. A knowledge of medicine and surgery goes without saying. In this conception of anatomy there is little room for petty details of structure, but there is an immense field for observation; study, research, and quickened interest.

Of the many thousands of students. whom it has been my privilege to teach I have never yet met one who has displayed the smallest interest in the purely anatomical constraction of, say, the human shoulder-joint. Show the same man, however, that this generalized structure per vades the whole vertebrate kingdom; that modifications of this structure necessarily occur in different animals according to the specific purposes to which the limb is put; that man is no exception to this law, but that his shoulderjoint is also modified for man's particular purposes, and that this modification necessarily means a liability to frequent dislocation, and that once it occurs muscular action will play an important part in the subseguent events of diagnosis and treatment-then that student's acute interest is not only aroused, but his reasoning powers are stimulated, his memory is quickened, and his observational powers are directed to the fact that he himself possesses a shoulder-joint. $\mathrm{He}$ has thus travelled a long way on the path of truth-the path that leads to the living and not tha dead.

Talke, again, the arch of the aorta, with its. long list of anatomical. relations. Their acquirement by memonics, rather than by reason, is but empiricism. On the other hand, show the student, if possible, a case of aneurysm of the aorta; explain the physical laws which underlie the occurrence of aneurysm of the aorta and of the popliteal artery; demonstrate that all the clinical phenomena of aneurysm are wholly referable to pressure on anatomical structures; elicit from the student which of the aortic relation, must be so pressed upon, and why, and what follows, and a totally different and more lasting impression is made upon the mind of the auditor than can possibly be made by a mere recital of names.

The human hand and foot, taught from a basis of evolu. tion, embryology, and morphology, leading on to function, and through function to a loss of function - that is, disease -is an altogether more useful and profitable business than any mere collection of osseous articulations, muscular attachments, and relations of trivial arteries. The central and autonomic nervous systems also furnish - as do, indeed, almost all parts of the human body-many splendid instances of the real conception of anatomy as a study of the living. That anatomy can no longer be regarded as mere details of the dead is amply proved by this last system. Dissections on the cadaver - even the most careful-display but one portion of the autonomic nervous system, namely, the vertebral sympathetic, and not even the whole of that. If this be the limits of the student's horizon it is not humanly possible for him to acquire any adequate knowledge of the structure and functions of the whole of this important system. Doubtless physiology will assist him, but his naked-eye anatomy will not. Similar remarks apply equally well to the central nervous system, to the surgically important epiphyses and lymphatics, and to muscular actions and control. If anatomy is not to lead to a study of life, and through life to disease and its treatment, its failure must be writ large across the page of medical history.

Passing in the next place to points of more technicality but of less importance, human anatomy is suffering rather badly at the moment from its nomenclature. 'That nomen clature is out of date, and requires urgent and prompt revision. To squabble as to whether we shall employ the Basle anatomical nomenclature or revert to the still more antiquated "old terminology" is to serve the science badly. The latter is hopeless confusion and the former is already out of date. 'There is no room in the anatomy of the living for anything but an accurate, scientific, and biological nomenclature which, within limits, shall be equally applicable to embryology and morphology. Such terms as "anterior" and "posterior" should give way to "ventral" and "dorsal," nor is there any scientific justifica. tion for the retention of such names as "inferior epignstric artery," as the artery is not "inferior" in any other animal but man. It is also open to question if we are justified, in view of modern neurologieal knowledge, in spealing of "branches of distribution" of both afferen. and efferent peripheral nerves. These criticisms notwithstanding, we owe much to the labours of the Basle Internationul Commission, amongst other things the elimination of rearly 25,000 useless synonyms from the already long list of the names of gross anatomy. That the Commission's work is now out of date is undoubted, and there is urgently wanted a new commission of English. speaking anatomists, physiologists, and clinicians to determine the main principles. to bo adopted in the nomenclature of known facts; leaving details to a smalle committe of the Commission. As anatomieal nomen clature concerns the whole medical profession, it would be well for clinicians to be-consulted. Much of the opposition towards the Basle nomenclature has arisen from ignorance of the principles involved, and from the fact that it was largely a purely anatomical commission. With the main principles determined, a smaller and permanent committee of, say, the Royal Society, is required to determine from time to time the terms to be employed for the new facts discovered by research. Recent work on the autonomic nervous system is a conspicuous example of the confusion which is arising from the chaotic and improper use of terms and expressions for which there is no official sanction and but little foundation in fact.

That anatomical textbooks abound in a mass of detail with little or no reference to function, and mueh of it of no importance, is easily verified by consulting them: Let one example suffice. The pectoralis minor muscle will be found described wit'. the most faithful attention to the minutest points of its attachments. Why any student should be expected to burden his memory to the exclusion of his reasoning and observational powers with such verbiage-one had almost said garbage-is difficult to understand. From the standpoint of biology they do not elicit the important truth that, in man, the muscle has undergone retrogiession from its more functional condition in the bird, which is in accordance with the great evolu. tionary laws underlying modification of structure to function; whilst from the standpoint of surgery the only important fact about the pectoralis minor muscle consists in its general relation to the ventral axillary wall, and to this, curiously enough, the student's attention is not directed by his textbools. Could not, then, much useless detail be eliminated from our anatomical textbooks, thus making room for facts of greater interest and wider applicability? Personally, I think it not only conld but should, though conscience compels me to admit that I have myself been guilty of much whici I also condemn. The real truth is that without the active co-operation of the clinician it is impossible for the anatomist to know how fal he may proceed with safety in the elimination of the unnecessary. It should, however, even now be the plain duty of the teacher to tell his students where, how, and why much of this detail can be dispensed with.

The limited conception of anatomy as a study of the dead has also tended to limit the field of research, as has also that other conception that anatomy is restricted to the study of Man. Its aim is undoubtedly Man, the living man, but its foundations are to be sought in the study of all vital phenomena. The fields of heredity, moiphology, and physical anthropology offer great and unrestricted possibilities to the anatomist of the living. The human cadaver offers few such fields.

This conception of liuman anatomy as a study of the living and not of the dead-if it be the true one, as experi. ence leads me to believe-necessarily implies some drastic and revolutionary changes in its mode of teaching, in its place in the medical curriculum, and in the position of the laboratories in which its study should be prosecuted The last mentioned should be as intiniately associated with a hospital as is possible. If that be not possible, then much of its higher teaching should be couducted in a hospital with the aid of a projection apparatus; the living subject, and the clinician. Its study should not be restricted to 
certain terms of the curriculum, bnt should be spread over most, if not all, the terms of that curriculum, and should be directly linked up in the form of team work with other subjects such as medicine, surgery, obstetrics, neurology, and the special senses. The actual dissecting can be completed in the earlier years of the curriculum with the elimination of much of the useless detail with which it is now encumbered. The supervision of this earlier part of the work can be safely entrusted to junior surgeons and recent graduates. Its higher and later study should be in the hands of the professional anatomist, who should him self be a member of the staff of the hospital in which his teaching and researches will be conducted. Under sncl conditions-which are not so Utopian as to be impossible of realization-the subject, the profession, and the patien would benefit enormously.

It may be argued that the extended field of observation which is here urged as being the province of the anatomist is altogether too large. That this is not so is shown by the number of living men who, in both their teachings and their writings, very efficiently cover this wider domain. What is more to the point is where such men are coming from in the near future. The social outlook has been so profoundly modified by the economic consequences of the Peace as to make it certain that no young medical man of promise and ability will nowadays wilfully or deliberately choose the life of denial which, on existing salaries, will be his only reward as an academic teacher of medical science. Neither the aniversities nor the profession need expect the advancement of medicine by research if the emolu. ments of such research are to compare none too fapourably with the daily wage of the manual labourer. - The caustic critic-himself possibly paying supertax-need not regard this as a personal "grouse." It is a very gennine fear for the future of a branch of medical science to which every practitioner owes so much.

To many the ideas lerein expressed will doubtless appeas heterodox and revolutionary. On the other hand, a recent visit to England has convinced me that there is a much larger number who are very cordially in agreement with the main conception of this paper, which is that anatomy is a study of the living, and that its methods require moditication. It is perhaps unnecessary to adduce evidence of the thesis, but it may be well to point out that the pages of Medical Education in Europre, published in 1912 by the Carnegie Foundation for the Advancement of Teaching, contain ample evidence of the fact that an anatomical institute sliould be in close co-operation with a hospital. The recently published report on the medical curriculum by the Edinburgh Pathological Club is simi. larly convincing as to the impessibility of teaching human anatomy in a water-tight compartment of that curriculum. The discussion at Cambridge in June, 1920, on the preliminary medical sciences-and particularly the eloquent words of Sir George Newman and Professor Arthur Keithintensifies the necessity for change in the relations of the ancillary sciences to medicine. As Osler remarked, "Biology teaches the problem of life at every point, and may claim, as no other science, completeness of view and a comprehension which pertains to it alone." This is verily the living anatomy herein advocated, as is also Keith's dictum that "Anatomy could be made a living practical part of medicine." Why is it not?

\section{A NOTE ON THE USE OF ANTIGONOCOCCAL SERUM."}

BY FRANCES IVENS, M.S.LoNd.,

HONORARY MEDICAI OFFICER. DISEASPG OF WOMEN, STANLEY HOSPITAI, LITERPOOT

The prevalence of gonorrhoea in young and otherwise healthy married women ${ }^{1}$ makes it peculiarly necessary noti only to improve technique but to utilize all available means to make conservative gyuaecological surgery a success in the presence of this infection. Until the last few years antigonococcal serum therapy has not been generally employed, although as early as 1895 de Christmas ${ }^{2}$ experimented with it in guinea-pigs and rab̆bits. Wassermann and Wertheim confirmed his

* Read at a clinical meeting of the Liverpool Medical Institution,
Ducember 16th, 1920 experiments, the former showing that the poison was contained in the body of the microbe, which did not belong to a diffusible group. These results were applied by Rogers and 'lory ${ }^{3}$ in 1906, and Parke Davis's anti. gonococcal serum was used successfully in the treatment of gonorrhoeal rheumatism. Recently Paraf ${ }^{4}$ pointed out the points of resemblance between the meningococcus and the gonococcus, and urged the necessity for methods of local application of the serum to bring it into inumediate contact with the microbe, as is done in the treatment of cerebro-spinal meningitis by intrathecal injections. Paraf supported his views by iuoculation experiments in the anterior chambers of rabbit's eyes, and by intrathecal injections into monkoys. With Nicolle's serum he cared 14 out of 16 cases of arthritis by the intra-articular injec. tion of serum. This serum is active, possessing agglutinating, bacteriolytic, and bactericidal qualities, and is endowed with therapeutic properties against different strains of gonococci.

Encouraged by the results obtained during the war by the use of specific serums in woand infection, and more especially in gas gangrene, ${ }^{5} \mathrm{I}$ determined a year ago to experiment with antigonococcal serum in the treatment of some of the cases of gonocorcal infection coming under my care. I employed serum in about 30 cases, in 22 of which tubal infection was the most marked feature. Endocervicitis was present in three, and in three cases of arthritis one had occurred during preganncy, another in the puerperium.

I adopted three methods of application. In one series I gave the serum subcutaneously diluted in normal saline, usually in a dose of 20 c.cm., repeated at intervals of a couple of days, every three days, or occa sionally a week, giving in all from 20 to 200 c.cm.

In another series, on the supposition that the toxin is not diffusible, I tried the intraperitoneal method. Where there were dripping pus tubes or a pyosalpinx the tube was washed out with normal saline, after being, if necessary, opened up. Conservative surgery was adopted when possible, both tubes, or at any rate one, being left. With a syringe $20 \mathrm{c.cm}$. of serum was injected into the tubes, sometimes into the ovary, and the residue left in the pouch of Douglas. The abdomen was then closed without drainage, and the Fowler position adopted. To avert anaphylactic shock a subeutaneous or rectal saline was given simultaneously. This method, which we employed em. pirically during the war, has been slown by Richet ${ }^{6}$ to have a scientific basis - namely, that sodium chloride has a protecting action against the assaulting infection. Lumière and Cherrotier ${ }^{7}$ have recently shown that other sodium salts act as well.

Thirdly, in a few cases of endocervicitis with profuse leucorrhoea $I$ tried serum packs in the vagina, alternating daily with packs moistened with equal parts of 10 per cent. salt solution and 5 per cent. carbolic acid. In one case 200 c.cm. of serum were used, but my limited supply did not permit me to utilize this method as frequently as I wished. The after-history of these local cases has been peculiarly good-one has recently become pregnant, another, who had had previous ineffective treatment ex tending over a couple of years, got quite well, all trace of gonococci disappearing.

In no case have I used serum intravenously, as it is the only method in which I have seen fatal anaplyylactic shock supervene after the use of serum. With repeated doses there is little doubt that it is safest to use the fractional method, and not to allow more than seven or eight days to intervene between the first and second doses.

With two exceptions all these patients were married women. Thirteen had no children, and nine one only-a striking percentage of sterility. All but three were between 20 and 30 years of age.

Every effort was made to confirm the diagnosis by bacteriological findings. The history and physical signs were generally ciear, and I have not included doabtfal cases. The existence of purulent vaginitis and of oph. thalmia neonatorum in the children was of diagnostic value. of the 30 cases subcutaneous injections were used in 19 , in 6 intratubal and peritoneal, in 3 vaginal packs, and in 2 cases of bartholinitis, serum dressings.

\section{Resultis.}

All the cases have made a good immediate recovery. In nearly all, either by personal investigation or thwough 